Review Article

$\mathrm{J}$ Exp Clin Med

2021; 38(S1): 11-16

doi: $10.52142 /$ omujecm.38.si.gastro.1

\title{
Diagnostic and therapeutic approaches for non-variceal upper gastrointestinal bleeding
}

\author{
Talat AYYILDIZ1,*ib, Mustafa Emre DUYGULU2 ${ }^{2}$
}

${ }^{1}$ Department of Gastroenterology, Faculty of Medicine, Ondokuz Mayıs University, Samsun, Turkey

${ }^{2}$ Department of Internal Medicine, Çarşamba State Hospital, Samsun, Turkey

\begin{abstract}
\begin{tabular}{ccccc}
\hline Received: 15.09 .2020 & $\bullet$ & Accepted/Published Online: 02.01 .2021 & • & Final Version: 18.03 .2021 \\
\hline
\end{tabular}
Abstract

Upper gastrointestinal bleeding (UGIB) is a common, life-threatening medical condition. Non-variceal causes account for more than $90 \%$ of bleeding episodes. Peptic ulcer disease is the most frequent cause of non-variceal UGIB. Patients present with hematemesis and/or melena but hematochezia might be present in patients with severe bleeding. Despite advances in diagnostic and therapeutic methods, mortality remains high in the elderly and patients with comorbidities. Endoscopy is the primary procedure that should be performed to identify the etiology of UGIB and for treatment purposes following adequate resuscitation of patients. Early endoscopy (within the first 24 hours) has considerably improved the clinical outcomes. A number of scoring systems are being used in patients with UGIB to identify the risk of complications, rebleeding risk, the need for interventional procedures and the risk of death. The most commonly used scoring tools are the Rockall score, Glasgow-Blatchford score and AIMS65 score. Primary treatment modalities include adequate resuscitation, intravenous fluid support, transfusion of red blood cell suspension, acid suppression therapy and administration of prokinetic agents. In general, angiography, computed tomography, technetium- $99 \mathrm{~m}-$ labeled red blood cell scintigraphy and capsule endoscopy may be used in patients whose bleeding cannot be detected endoscopically. Interventional radiological procedures should be initially performed for hemorrhages that cannot be stopped endoscopically and surgical options should be considered when interventional radiological procedures are out of reach or unsuccessful.
\end{abstract}

Keywords: upper gastrointestinal bleeding, endoscopy, scintigraphy, non-variceal bleeding

\section{Introduction}

Upper gastrointestinal bleeding (UGIB) is a common, lifethreatening medical condition. UGIB is defined as bleeding originating from a source proximal to the ligament of Treitz including esophagus, stomach and duodenum. UGIB is broadly divided into two groups as variceal and non-variceal hemorrhages. Gastroduodenal ulcers are the leading cause of non-variceal UGIB (Hunt et al., 1995). Non-variceal causes account for more than $90 \%$ of bleeding episodes. Clinically, it may present with massive bleeding as well as slow, chronic bleeding. Despite the advances in diagnostic and therapeutic methods, bleeding-related mortality has not changed significantly in comparison to previous years because the mortality is still high in the elderly and the patient population with comorbidities (Wilcox and Clark, 1999; Hwang et al., 2012). In Western countries, the reported annual incidence of UGIB in adults ranges from 103 to 172 episodes per 100,000 population (Rockall, et al., 1995; Van Leerdam et al., 2003). Hospitalizations for UGIB have decreased by nearly $20 \%$ in the last decade due to reduction of peptic ulcer bleeding as a result of the use of anti-secretory drugs and decreased prevalence of Helicobacter pylori (Laine, et al., 2012). The mainstay of patient management is achieving hemodynamic stability, followed by performing endoscopy for the purposes of diagnosis and treatment. Early endoscopy within the first 24 hours have greatly improved clinical outcomes (Vergara, et al., 2014). In $80 \%$ of the cases, non-variceal UGIB stops spontaneously (Van Leerdam et al., 2003). At the same time, early risk stratification of patients is important for treatment planning including the timing of endoscopic treatment and Glasgow-Blatchford, Rockall and AIMS65 scores are commonly used for this purpose (Alzoubaidi, et al., 2019). In the case of persistent and recurrent bleeding, repeat upper endoscopy should be performed initially, followed by consideration of interventional radiology procedures such as trans arterial chemoembolization (TACE) and surgical treatment options (Gralnek et al., 2015).

2. Etiology of non-variceal upper gastrointestinal bleeding The etiology of non-variceal UGIB most commonly involves peptic ulceration/inflammation (most prevalent, approximately $50 \%$ ), vascular lesions, congestive gastropathy, malignant 
lesions and other causes (Mallory-Weiss tears, Cameron ulcers, anastomotic ulcers, post-procedural hemorrhages). The etiology cannot be determined in about $10 \%$ of the patients (Table 1) (Naseer et al., 2020).

Table 1. Causes of non-variceal gastrointestinal bleeding

\begin{tabular}{|l|l|}
\hline Ulcer / Inflammation & $\begin{array}{l}\text { Peptic ulcer disease } \\
\text { Esophagitis, gastritis, duodenitis } \\
\text { Anastomotic ulcers }\end{array}$ \\
\hline \multirow{3}{*}{ Vascular Lesions } & $\begin{array}{l}\text { Gastric antral vascular ectasia } \\
\text { (GAVE) } \\
\text { Dieulafoy lesion } \\
\text { Angiodysplasia } \\
\text { Aorta-enteric fistula }\end{array}$ \\
\hline Congestive Gastropathy & Portal hypertensive gastropathy \\
\hline Malignancies & $\begin{array}{l}\text { Gastric, esophageal tumors } \\
\text { Metastatic tumors }\end{array}$ \\
\hline Other & $\begin{array}{l}\text { Mallory Weis tear } \\
\text { Cameron ulcer }\end{array}$ \\
\hline
\end{tabular}

Peptic ulcer disease is defined as a lesion that penetrates into the muscularis mucosa layer of the gastric and duodenal mucosa and is the most common cause of UGIB. Helicobacter pylori infection, the use of non-steroidal anti-inflammatory drugs, physiological stress and increased gastric acid secretion are risk factors for bleeding (Hunt et al., 1995). Esophagitis is a frequent cause of UGIB and its risk factors include gastroesophageal reflux disease, the use of certain medications and infections (Da Costa et al., 2001; Guntipalli et al., 2014). Gastritis and duodenitis are inflammation-mediated mucosal injuries and although these are frequent endoscopic findings, they are less likely to cause hemorrhage and usually selflimiting (Guntipalli et al., 2014).

Vascular lesions of the gastrointestinal tract that may cause UGIB to include angiodysplasia, Dieulafoy's lesion and gastric antral vascular ectasia (GAVE). Angiodysplasia is the most common vascular abnormality of the gastrointestinal tract. In the upper GI tract, angiodysplasias are mostly found in the stomach, duodenum but rarely in the esophagus. Its pathogenesis has not been fully elucidated. Endoscopic diagnosis of angiodysplasia can sometimes be challenging because the lesions are small and may resemble fresh bleeding. Rarely, the diagnosis of angiodysplasia can be made by radiological or surgical modalities. Dieulafoy's lesion is a vascular abnormality consisting of dilated, aberrant submucosal vessels and an infrequent cause of UGIB. The majority of the lesions are located in the stomach. Dieulafoy's lesions exhibit an intermittent bleeding pattern and therefore, are identified at a low rate on initial endoscopic examination (Marangoni, et al., 2009). GAVE also known as 'watermelon stomach' is a rare but important cause of UGIB. Endoscopically, it is characterized by linear, diffuse erythematous stripes that radiate from the pylorus to the antrum, giving the appearance of watermelon streaks. The etiology of GAVE is not clear (Jabbari et al., 1984). MalloryWeiss syndrome is marked by longitudinal superficial mucosal lacerations (Mallory-Weiss tears). Mallory-Weiss tears are often located in the gastroesophageal junction and may extend proximally to involve the stomach and duodenum. Excessive alcohol consumption is the most common cause. Risk factors include hiatal hernia, hyperemesis gravidarum and gastroesophageal reflux disease. Repeated acts that cause a sudden and severe increase in the intra-abdominal pressure such as retching and vomiting precipitate Mallory-Weiss syndrome. Longitudinal tears may progress and extend deep into submucosal arteries and veins, causing bleeding. Bleeding is often self-limiting and recurs infrequently (Kortas, et al., 2001; Rawla and Devasahayam, 2019). Gastrointestinal tumors, primary gastrointestinal tumors, metastatic tumors and locally invasive tumors may cause UGIB. Gastric tumors are the most common cause of UGIB (Kim and Choi, 2015). Unlike other non-variceal UGIB, the success rate of endoscopy is low in bleeding from gastrointestinal tumors and rebleeding after a short time occurs in about $80 \%$ of the cases. Surgical or radiological intervention may be required when the endoscopic procedure fails (Adler et al., 2004).

\section{Diagnostic and therapeutic approaches for the management of bleeding}

There have been considerable advances in the management of UGIB in recent years. However, advanced age and comorbid conditions are still risk factors for many patients (Lanas, 2010) The management of bleeding consists of 3 approaches: preendoscopy, endoscopy, and post-endoscopy. For treatment planning, it is important to question the presence of comorbidities (coronary artery disease, pulmonary disease, renal disease, heart failure, chronic liver disease). It allows identification of thresholds for transfusion of red blood cell suspension and intravenous fluid support. History of medication use (non-steroidal anti-inflammatory drugs, antiplatelet drugs, anticoagulants) is crucial in terms of the balance between bleeding control and cardiovascular risk as well as to determine whether the medication should be discontinued and when it should be resumed. Studies have shown that routine nasogastric intubation does not offer any clinically relevant benefit for patients. The presence of coffee ground material or fresh blood in the nasogastric content indicates UGIB (Lanas, 2010). A number of scoring systems are being used in patients with UGIB to identify the risk of complications, rebleeding risk, the need for interventional procedures and mortality risk. These scoring systems are categorized into three groups as those including endoscopic parameters, those with both clinical and endoscopic parameters and those with clinical parameters alone. It is recommended that these scoring tools be used in an early stage in patients presenting with UGIB (Barkun et al., 2010). The most widely used scoring systems are Forrest classification, Rockall score, Glasgow-Blatchford score and AIMS65 score.

\subsection{Initial resuscitation}

For a patient with a preliminary diagnosis of UGIB, the first thing to do is to assess the patient's airway, breathing and circulation. Oral intake of the patient is stopped. Adequate peripheral access should be achieved with two large-bore (18 
gauge) catheters and a central venous catheter inserted when necessary. Blood pressure, oxygen saturation and heart rate should be monitored. Patients should be provided intravenous fluid support without delay. It is particularly important to ensure hemodynamic control and stabilization with intravenous fluid support prior to endoscopy; this way, the risk of treatment-related complications is reduced (Baradarian et al., 2004). No difference in mortality was observed in a metaanalysis comparing colloids and crystalloids for fluid resuscitation in critically ill patients (Perel and Roberts, 2012). The quantity of fluid to be administered is adjusted according to the hemodynamic state of the patient.

\subsection{Anemia and thrombocytopenia}

In patients with UGIB, red blood cell (RBC) transfusion is often required to maintain tissue perfusion. The decision for transfusion is made individually on a patient basis. Hemoglobin threshold for transfusion is a controversial topic. In hemodynamically unstable patients and patients with severe bleeding, transfusion up to higher thresholds is needed, as hemoglobin values will decrease even further with intensive fluid treatment. Reduced transfusion volume is associated with decreased mortality in hemorrhagic patients; this has led to the consideration of the negative effects of over transfusion on hemostasis (Crooks et al., 2011). Transfusion of red blood cell suspension is needed in patients with active hemorrhage regardless of hemoglobin level. The liberal transfusion strategy aims transfusion to patients with hemoglobin values below 9$10 \mathrm{~g} / \mathrm{L}$, whereas the restrictive transfusion strategy targets the patient population with hemoglobin values below 7-8 g/L. In a meta-analysis, patients treated with the restrictive strategy had lower rates of mortality and rebleeding in comparison to patients treated with the liberal strategy (Odutayo et al., 2017). If there is a concern for potential harm to the patient from ischemia (e.g., coronary artery disease) related to anemia, the hemoglobin value is kept above $9 \mathrm{~g} / \mathrm{L}$. In the presence of active ischemia, RBC transfusion should be given by keeping the hemoglobin value at $10 \mathrm{~g} / \mathrm{L}$. In patients with UGIB, transfusion of platelet suspension is warranted at a platelet count less than 50.000 cells/microliters. There is no evidence demonstrating the benefit of platelet transfusion suspension in patients receiving antiplatelet drugs; therefore, it should be decided on a patient basis.

\subsection{Use of antiplatelet and anticoagulant medications}

Increasing use of antiplatelet and anticoagulant drugs is a risk factor for UGIB and 44\% of patients take these medications (Chang et al., 2015; Dunne et al., 2019). Anticoagulant and antiplatelet drugs are discontinued in UGIB patients when possible. However, potential harms from discontinuation of these drugs should be weighed against the risks of bleeding prior to stopping these therapies and the decision to discontinue or administer an antidote should be made individually for each patient by consulting the departments that started the patient on these medications.
Guidelines suggest an INR (International Normalized Ratio) value less than 2.5 before performing endoscopy (Acosta et al., 2016). Fresh frozen plasma is usually used in patients with a high INR value and prothrombin complex concentrate (PCC) is recommended to achieve a rapid INR reduction in patients with life-threatening bleeding (Maltz et al., 2000). Limited data are available for novel oral anticoagulants (NOACs) which have a short half-life of 5 to 17 hours. PCC may be used in severe bleeding (Veitch et al., 2016). There are no sufficient data on the use of idaricuzimab as an antidote for dabigatran and andexanet alfa (a recombinant modified Factor Xa) for Factor Xa inhibitors in patients with UGIB.

\subsection{Acid suppression}

Gastric acid suppression contributes to achieving hemostasis. The use of proton-pump inhibitors (PPIs) prior to endoscopy reduces the symptoms of severe bleeding and the need for endoscopic treatment. Patients are started on PPI treatment on the day of admission. Optimal dosage is not clear; studies showed that PPI treatment administered as an intravenous 80 $\mathrm{mg}$ bolus dose followed by continuous infusion at $8 \mathrm{mg} / \mathrm{h}$ for 72 hours reduced the rates of rebleeding and mortality compared to placebo and non-PPI treated groups (Laine and McQuaid, 2009). Some guidelines recommend intermittent use of high-dose intravenous or oral PPI ( $80 \mathrm{mg}$ bolus, followed by 80 to $160 \mathrm{mg}$ daily in divided doses) (Gralnek et al., 2015). Patients with peptic ulcer should receive a PPI once daily for 4 -8 weeks after a UGIB.

\subsection{Prokinetic agents and tranexamic acid}

Prokinetic agents such as erythromycin and metoclopramide improve the endoscopic visibility by accelerating gastric emptying when given prior to endoscopy and they may also reduce the need for a second-look endoscopy. Erythromycin, administered as a single dose at 20-120 minutes before endoscopy, has been shown to provide better endoscopic visibility, shorter duration of endoscopy and reduced need for second endoscopy (Frossard et al., 2002). Tranexamic acid is an antifibrinolytic agent; studies have shown that it has no benefit in the treatment of gastrointestinal bleeding and predisposes to venous thrombus (Roberts et al., 2020).

\subsection{Risk Scores}

In addition to bleeding, mortality has been shown to be associated with other clinical parameters (e.g., age, comorbidities, shock, endoscopic diagnosis, hemoglobin levels, ulcer diameter, need for transfusion), all of which can have an impact on the prognosis in patients with non-variceal UGIB (Nahon et al., 2012; Monteiro, et al., 2016). The Forrest classification is used to predict the rebleeding risk of patients based on endoscopic findings (Table 2). The most commonly used scoring tool is the Rockall score with both clinical and endoscopic components. Possible scores range from 0 to 11 points. 
Table 2. Forrest classification

\begin{tabular}{|c|c|c|}
\hline $\begin{array}{l}\text { Forrest } \\
\text { Score }\end{array}$ & Endoscopic Appearance & $\begin{array}{c}\text { Risk of } \\
\text { Rebleeding } \\
(\%)\end{array}$ \\
\hline $1 \mathbf{a}$ & $\begin{array}{l}\text { Ulcer with active pulsating } \\
\text { bleeding }\end{array}$ & 90 \\
\hline $1 b$ & $\begin{array}{l}\text { Ulcer with active non-pulsating } \\
\text { bleeding }\end{array}$ & $10-20$ \\
\hline $2 \mathbf{a}$ & $\begin{array}{l}\text { Ulcer with a visible nonbleeding } \\
\text { vessel }\end{array}$ & 50 \\
\hline $2 \mathbf{b}$ & Ulcer with an adherent clot & $25-30$ \\
\hline 2c & Ulcer with hematin on ulcer base & $7-10$ \\
\hline 3 & $\begin{array}{l}\text { Ulcer with a clean base without } \\
\text { signs of recent bleeding }\end{array}$ & $3-5$ \\
\hline
\end{tabular}

Endoscopic findings are not included in the calculation of clinical Rockall score and scoring is done with maximum seven points (Table 3) (Rockall, et al., 1996). The GlasgowBlatchford score (GBS) consists of eight clinical and laboratory parameters. Scores range between 0 and 23 points. Higher scores indicate greater need for endoscopy. The major advantage of this scoring tool is its ability to identify low-risk patients who do not need to be admitted to hospital. A patient suspected of having an UGIB whose score is 0 can be safely followed on an outpatient basis (Table 4) (Blatchford, et al., 2000; Stanley et al., 2009).

Table 3. Rockall scoring system

\begin{tabular}{|c|c|c|c|c|}
\hline Variable/ Score & $\mathbf{0}$ & 1 & 2 & 3 \\
\hline Age & $<60$ & 60-79 & $80 \geq$ & \\
\hline Shock & No shock & $\begin{array}{c}\text { Blood } \\
\text { pressure }>100 \\
\text { Pulse } \geq 100\end{array}$ & $\begin{array}{c}\text { Blood pressure }<100 \\
\text { Pulse }>100\end{array}$ & \\
\hline Comorbidity & None & & $\begin{array}{c}\text { Circulatory failure/coronary } \\
\text { artery disease }\end{array}$ & $\begin{array}{l}\text { Renal failure } \\
\text { Liver failure } \\
\text { Disseminated } \\
\text { malignancy }\end{array}$ \\
\hline Diagnosis & $\begin{array}{c}\text { Mallory-Weiss } \\
\text { syndrome/no pathology }\end{array}$ & $\begin{array}{l}\text { All other } \\
\text { diagnosis }\end{array}$ & $\begin{array}{l}\text { Malignancy of the upper } \\
\text { gastrointestinal tract }\end{array}$ & \\
\hline $\begin{array}{l}\text { Endoscopic signs of } \\
\text { bleeding }\end{array}$ & None/dark spot & & $\begin{array}{l}\text { Blood/adherent clot/visible or } \\
\text { spurting vessel }\end{array}$ & \\
\hline
\end{tabular}

Table 4. Glasgow-Blatchford scoring system

\begin{tabular}{|c|c|}
\hline Variable & Score \\
\hline \multicolumn{2}{|l|}{ Blood urea nitrogen $(\mathrm{mmol} / \mathrm{L})$} \\
\hline $6.5-8$ & 2 \\
\hline $8-10$ & 3 \\
\hline $10-25$ & 4 \\
\hline$>25$ & 6 \\
\hline \multicolumn{2}{|l|}{ Hemoglobin for men $(\mathrm{g} / \mathrm{L})$} \\
\hline $120-130$ & 1 \\
\hline $100-120$ & 3 \\
\hline$<100$ & 6 \\
\hline \multicolumn{2}{|l|}{ Hemoglobin for women $(\mathrm{g} / \mathrm{L})$} \\
\hline $100-120$ & 1 \\
\hline$<100$ & 6 \\
\hline \multicolumn{2}{|l|}{ Systolic blood pressure $(\mathrm{mm} / \mathrm{hg})$} \\
\hline $100-109$ & 1 \\
\hline $90-99$ & 2 \\
\hline$<90$ & 3 \\
\hline Pulse $\geq 100$ & 1 \\
\hline \multicolumn{2}{|l|}{ Other markers } \\
\hline Presentation with melena & 1 \\
\hline Presentation with syncope & 2 \\
\hline Hepatic disease & 2 \\
\hline Cardiac failure & 2 \\
\hline
\end{tabular}

The AIMS65 score is an acronym of albumin, INR, alteration in mental status, systolic blood pressure and age. It is a clinical risk scoring tool and the score is calculated by assigning one point for each of the aforementioned components (for a total of five scores). The presence of two or more components indicates a higher risk of mortality (Table 5) (Saltzman et al., 2011).
Table 5. AIMS65 scoring system

\begin{tabular}{|l|c|}
\hline \multicolumn{1}{|c|}{ Variable } & Score \\
\hline Albumin $<3 \mathrm{~g} / \mathrm{dL}$ & 1 \\
$\mathrm{INR}>1.5$ & 1 \\
Systolic Blood Pressure $<90 \mathrm{~mm} / \mathrm{Hg}$ & 1 \\
Altered Mental Status & 1 \\
Age $>65$ year & 1
\end{tabular}

\subsection{Endoscopy}

Endoscopic examination is recommended for UGIB patients within the first 24 hours after admission for diagnostic and therapeutic purposes. This time interval is 12 hours in patients with impaired hemodynamic state and suspicion of variceal bleeding (Sung et al., 2011). Endoscopic treatment should be instituted following adequate resuscitation and hemodynamic stabilization. In patients with a higher risk of mortality and bleeding ( $\mathrm{GBS} \geq 12$ ), clinical outcomes were not different between those undergoing early endoscopy (within 6-24 hours) and those treated with emergency endoscopy (within 0-6 hours) (Lau et al., 2020). The diagnosis and treatment of UGIB are conducted by endoscopic examination. In general, angiography, computed tomography, technetium-99m-labeled red blood cell scintigraphy and capsule endoscopy may be used in patients whose bleeding cannot be detected endoscopically. The colonoscopic examination is planned to identify colonrelated etiologies for patients in whom a bleeding focus cannot be demonstrated by endoscopy.

Epinephrine injections, argon plasma coagulation, heater probe and endoscopic clips are the methods used in endoscopic 
treatment. In the case of failure of conventional treatments, over the scope clips, hemostatic powder, endoscopic suture, endoscopic band ligation, coagrasper or hemostatic forceps, endoscopic ultrasound-guided angiography, cryotherapy, radiofrequency ablation and endoscopic laser coagulation are newer treatment modalities that can be used in UGIB (Naseer et al., 2020). Firstly, repeat endoscopy should be done in a recurring UGIB episode. Interventional radiological procedures should be initially performed for hemorrhages that cannot be stopped endoscopically and surgical options should be considered when interventional radiological procedures are out of reach or unsuccessful. The transarterial chemoembolization (TACE) procedure is recommended for bleeding that persists after optimal endoscopic treatment (Gralnek et al., 2015).

\section{Conclusion}

Currently, non-variceal upper gastrointestinal bleeding is still a common condition. There have been considerable advances in the endoscopic treatment modalities in the last decade. It is important to determine the risk score of the patients in an early stage. Patients should be evaluated and managed thoroughly taking into account all aspects of their condition due to high numbers of patients with comorbidities, concomitant use of antiplatelet and anticoagulant drugs. Hemostatic powder, over the scope clips, endoscopy guided by Doppler probes are newly developed endoscopic techniques for use in patients in whom bleeding cannot be controlled with conventional endoscopic interventions.

\section{Conflict of interest}

All authors declare no conflict of interest regarding this manuscript.

\section{Acknowledgments}

No competing financial interests exist.

\section{References}

1. Acosta, R.D., Abraham, N.S., Chandrasekhara, V., Chathadi, K.V., Early, D.S., Eloubeidi, M.A., Evans, J.A., Faulx, A.L., Fisher, D.A., Fonkalsrud, L., Hwang, J.H., Khashab, M.A., Lightdale, J.R., Muthusamy, V.R., Pasha, S.F., Saltzman, J.R., Shaukat, A., Shergill, A.K., Wang, A., Cash, B.D., DeWitt, J.M, 2016. The management of antithrombotic agents for patients undergoing GI endoscopy. Gastrointest. Endosc. 83(1), 3-16.

2. Adler, D.G., Leighton, J.A., Davila, R.E., Hirota, W.K., Jacobson, B.C., Qureshi, W.A., Rajan, E., Zuckerman, M.J., Fanelli, R.D., Hambrick, R.D., Baron, T., Faigel, D.O., ASGE, 2004. ASGE guideline: the role of endoscopy in acute non-variceal upper-GI hemorrhage. Gastrointest. Endosc. 60(4), 497-504.

3. Alzoubaidi, D., Lovat, L. B., Haidry, R. 2019. Management of nonvariceal upper gastrointestinal bleeding: where are we in 2018 ? Frontline Gastroenterol, 10(1), 35-42.

4. Baradarian, R., Ramdhaney, S., Chapalamadugu, R., Skoczylas, L., Wang, K., Rivilis, S., Remus, K., Mayer, I., Iswara, K., Tenner, S., 2004. Early intensive resuscitation of patients with upper gastrointestinal bleeding decreases mortality. Am. J. Gastroenterol., 99(4), 619-622.
5. Barkun, A. N., Bardou, M., Kuipers, E. J., Sung, J., Hunt, R. H., Martel, M., Sinclair, P., 2010. International consensus recommendations on the management of patients with nonvariceal upper gastrointestinal bleeding. Ann. Intern. Med. 152(2), 101-113.

6. Blatchford, O., Murray, W. R., Blatchford, M., 2000. A risk score to predict need for treatment for uppergastrointestinal haemorrhage. Lancet. 356 (9238), 1318-1321.

7. Chang, H.Y., Zhou, M., Tang, W., Alexander, G. C., Singh, S., 2015. Risk of gastrointestinal bleeding associated with oral anticoagulants: population based retrospective cohort study. Bmj, 350 .

8. Crooks, C., Card, T., West, J., 2011. Reductions in 28-day mortality following hospital admission for upper gastrointestinal hemorrhage. Gastroenterology, 141(1), 62-70.

9. Da Costa, N., Cadiot, G., Merle, C., Jolly, D., Bouché, O., Thiéfin, G., Zeitoun, P., 2001. Bleeding reflux esophagitis: a prospective 1year study in a university hospital. Am. J. Gastroenterol. 96(1), 4751.

10. Dunne, P. D., Laursen, S. B., Laine, L., Dalton, H. R., Ngu, J. H., Schultz, M., Rahman, A., Anderloni., A., Murray, I., A., Stanley, A. J., 2019. Previous use of antithrombotic agents reduces mortality and length of hospital stay in patients with high-risk upper gastrointestinal bleeding. Clin. Gastroenterol. Hepatol. 17(3), 440447. e442.

11. Frossard, J. L., Spahr, L., Queneau, P. E., Giostra, E., Burckhardt, B., Ory, G., Hadengue De Saussure, P., Armenian, B., De Peyer, R., A., 2002. Erythromycin intravenous bolus infusion in acute upper gastrointestinal bleeding: a randomized, controlled, doubleblind trial. Gastroenterology, 123(1), 17-23.

12. Gralnek, I., Dumonceau, J., Kuipers, E., Lanas, A., Sanders, D., Kurien, M., Marmo, R., 2015. Diagnosis and management of nonvariceal upper gastrointestinal hemorrhage: European Society of Gastrointestinal Endoscopy (ESGE) Guideline. Endoscopy, 47(10), a1-46-a46.

13. Guntipalli, P., Chason, R., Elliott, A., Rockey, D. C., 2014. Upper gastrointestinal bleeding caused by severe esophagitis: a unique clinical syndrome. Dig. Dis. Sci. 59(12), 2997-3003.

14. Hunt, R. H., Malfertheiner, P., Yeomans, N. D., Hawkey, C. J., Howden, C. W., 1995. Critical issues in the pathophysiology and management of peptic ulcer disease. Eur. J. Gastro. Hepatol. 7(7), 685-699.

15. Hwan J.H., Fisher, D.A., Ben-Menachem, T., Chandrasekhara, V., Chathadi, K., Decker, G.A., Early, D.S., Evans, J.A., Fanelli, R.D., Foley, K., Fukami, N., Jain, R., Jue, T.L., Khan, K.M., Lightdale, J., Malpas, P.M., Maple, J.T., Pasha, S., Saltzman, J., Sharaf, R., Shergill, A.K., Dominitz, J.A., Cash, B.D., 2012. The role of endoscopy in the management of acute non-variceal upper GI bleeding. Gastrointest. Endosc. 75(6), 1132-1138.

16. Jabbari, M., Cherry, R., Lough, J. O., Daly, D. S., Kinnear, D. G., Goresky, C. A., 1984. Gastric antral vascular ectasia: the watermelon stomach. Gastroenterology. 87(5), 1165-1170.

17. Kim, Y.-I., Choi, I. J., 2015. Endoscopic management of tumor bleeding from inoperable gastric cancer. Clin. Endosc 48(2), 121.

18. Kortas, D. Y., Haas, L. S., Simpson, W. G., Nickl III, N. J., Gates Jr, L. K., 2001. Mallory-Weiss tear: predisposing factors and predictors of a complicated course. Am. J. Gastroenterol. 96 (10), 2863-2865.

19. Laine, L., McQuaid, K. R., 2009. Endoscopic therapy for bleeding ulcers: an evidence-based approach based on meta-analyses of randomized controlled trials. Clin. Gastroenterol. Hepatol. 7 (1), $33-47$. 


\section{Ayyildiz and Duygulu / J Exp Clin Med}

20. Laine, L., Yang, H., Chang, S.-C., Datto, C., 2012. Trends for incidence of hospitalization and death due to GI complications in the United States from 2001 to 2009. Am. J. of Gastroenterol. 107(8), 1190-1195.

21. Lanas, A., 2010. Upper GI Bleeding-Associated Mortality: challenges to improving a resistant outcome. Am. J. Gastroenterol. 105(1), 90-92.

22. Lau, J.Y.W., Yu, Y., Tang, R.S.Y., Chan, H.C.H., Yip, H.C., Chan, S.M., Luk, S.W.Y., Wong, S.H., Lau, L.H.S., Lui, R.N., Chan, T.T., Mak, J.W.Y., Chan, F.K.L., Sung, J.J.Y., 2020. Timing of endoscopy for acute upper gastrointestinal bleeding. N. Eng. J. Med. 382(14), 1299-1308.

23. Maltz, G. S., Siegel, J. E., Carson, J. L., 2000. Hematologic management of gastrointestinal bleeding. Gastroenterol. Clin. North Am. 29(1), 169-187.

24. Marangoni, G., Cresswell, A. B., Faraj, W., Shaikh, H., Bowles, M. J., 2009. An uncommon cause of life-threatening gastrointestinal bleeding: 2 synchronous Dieulafoy lesions. J. Pediatr. Surg. 44(2), 441-443.

25. Monteiro, S., Gonçalves, T. C., Magalhães, J., Cotter, J., 2016. Upper gastrointestinal bleeding risk scores: Who, when and why? World. J. Gastrointest. Pathophysiol. 7(1), 86.

26. Nahon, S., Hagège, H., Latrive, J.P., Rosa, I., Nalet, B., Bour, B., Faroux, R., Gower, P., Arpurt, J.P., Denis, J., Henrion, J., Rémy, A.J., Pariente, A., 2012. Epidemiological and prognostic factors involved in upper gastrointestinal bleeding: results of a French prospective multicenter study. Endoscopy, 44(11), 998-1008.

27. Naseer, M., Lambert, K., Hamed, A., Ali, E., 2020. Endoscopic advances in the management of non-variceal upper gastrointestinal bleeding: A review. World J. Gastrointest. Endosc. 12(1), 1.

28. Odutayo, A., Desborough, M.J., Trivella, M., Stanley, A.J., Dorée, C., Collins, G.S., Hopewell, S., Brunskill, S.J., Kahan, B.C., Logan, R.F., Barkun, A.N., Murphy, M.F., Jairath, V., 2017. Restrictive versus liberal blood transfusion for gastrointestinal bleeding: a systematic review and meta-analysis of randomised controlled trials. Lancet Gastroenterol. Hepatol. 2(5), 354-360.

29. Perel, P., Roberts, I., 2012. Colloids versus crystalloids for fluid resuscitation in critically ill patients. Cochrane Database of Systematic Reviews (6).

30. Rawla, P., Devasahayam, J. (2019). Mallory Weiss Syndrome. In StatPearls [Internet]: StatPearls Publishing.

31. Roberts, I., Shakur-Still, H., Afolabi, A., Akere, A., Arribas, M., Brenner, A., Hussain, I., 2020. Effects of a high-dose 24-h infusion of tranexamic acid on death and thromboembolic events in patients with acute gastrointestinal bleeding (HALT-IT): an international randomised, double-blind, placebo-controlled trial. Lancet. 395(10241), 1927-1936.

32. Rockall, T., Logan, R., Devlin, H., Northfield, T., 1995. Incidence of and mortality from acute upper gastrointestinal haemorrhage in the United Kingdom. Bmj. 311(6999), 222-226.

33. Rockall, T., Logan, R., Devlin, H., Northfield, T. 1996. Risk assessment after acute upper gastrointestinal haemorrhage. Gut. 38(3), 316-321.

34. Saltzman, J. R., Tabak, Y. P., Hyett, B. H., Sun, X., Travis, A. C., Johannes, R. S., 2011. A simple risk score accurately predicts inhospital mortality, length of stay, and cost in acute upper GI bleeding. Gastrointest. Endosc. 74(6), 1215-1224.

35. Stanley, A.J., Ashley, D., Dalton, H.R., Mowat, C., Gaya, D.R., Thompson, E., Warshow, U., Groome, M., Cahill, A., Benson, G., Blatchford, O., Murray, W., 2009. Outpatient management of patients with low-risk upper-gastrointestinal haemorrhage: multicentre validation and prospective evaluation. Lancet. 373(9657), 42-47.

36. Sung, J.J., Chan, F.K., Chen, M., Ching, J.Y., Ho, K.Y., Kachintorn, U., Kim, N., Lau, J.Y., Menon, J., Rani, A.A., Reddy, N., Sollano, J., Sugano, K., Tsoi, K.K., Wu, C.Y., Yeomans, N., Vakil, N., Goh, K.L, 2011. Asia-Pacific Working Group consensus on non-variceal upper gastrointestinal bleeding. Gut. 60(9), 11701177.

37. Van Leerdam, M., Vreeburg, E., Rauws, E., Geraedts, A., Tijssen, J., Reitsma, J., Tytgat, G., 2003. Acute upper GI bleeding: Did anything change? Time trend analysis of incidence and outcome of acute upper GI bleeding between 1993/1994 and 2000. The Am. J. Gastroenterol. 98(7), 1494-1499.

38. Veitch, A.M., Vanbiervliet, G., Gershlick, A.H., Boustiere, C., Baglin, T.P., Smith, L.A., Radaelli, F., Knight, E., Gralnek, I.M., Hassan, C., Dumonceau, J.M., 2016. Endoscopy in patients on antiplatelet or anticoagulant therapy, including direct oral anticoagulants: British Society of Gastroenterology (BSG) and European Society of Gastrointestinal Endoscopy (ESGE) guidelines. Gut. 65(3), 374-389.

39. Vergara, M., Bennett, C., Calvet, X., Gisbert, J. P., 2014. Epinephrine injection versus epinephrine injection and a second endoscopic method in high-risk bleeding ulcers. Cochrane Database Syst. Rev. 13, (10).

40. Wilcox, C. M., Clark, W. S., 1999. Causes and outcome of upper and lower gastrointestinal bleeding: the Grady Hospital experience. South Med. J. 92(1), 44-50. 